\title{
PRIMERAS CONCLUSIONES SOBRE EL CULTO Y LA ICONOGRAFÍA DE SANTIAGO EL MAYOR EN LA CIUDAD DE ROMA
}

\author{
POR \\ Rosa VÁzQuez SANTOS \\ Investigadora Parga Pondal de la S. A. de Xestión do Plan Xacobeo
}

\begin{abstract}
El presente artículo ofrece una topografía artística y devocional de Santiago el Mayor en la ciudad de Roma a través del estudio de las iglesias y hospitales que estuvieron bajo su titularidad. De la consulta sistemática de las principales fuentes bibliográficas y documentales, principalmente topográficas e iconográficas, hemos obtenido dos discursos que se entrecruzan: uno cronológico que permite fechar la fundación, desaparición, derribo o cambio de titularidad de las iglesias estudiadas, confirmando un fuerte desarrollo del culto compostelano entre el Jubileo de 1300 y finales del siglo XV, así como un acelerado declive a lo largo del siglo XVI y primeras décadas del XVII; el segundo discurso, geográfico, ratifica la importancia de la basílica de San Pedro, sus reliquias y peregrinos para el primer desarrollo del culto jacobeo y, posteriormente, la relación entre los hospitales e iglesias jacobeas y la peregrinación a las principales basílicas de la ciudad. A todo ello se suma el estudio de las obras de arte, conservadas o perdidas, reliquias, procesiones y otras manifestaciones litúrgicas, completando un trabajo que pretende ser una primera mirada conclusiva sobre el tema.
\end{abstract}

Palabras clave: Santiago el Mayor; Roma; Iglesias; Plantas históricas de Roma; Guías históricas de Roma; Arte; Culto; Iconografía.

This article deals with the artistic and devotional topography associated with St. James the Great in the city of Rome based on a study of the churches and pilgrim hospitals under his patronage. An examination of the principal bibliographical and documental sources, especially those concerned with topography and iconography, has led to two aspects that converge: one is chronological, and has allowed us to date the foundation, disappearance, destruction or change of patronage of the churches, confirming a strong development of the cult of Saint James between the Jubilee Year 1300 and the end of the $15^{\text {th }}$ century, and subsequently a rapid decline throughout the $16^{\text {th }}$ century into the first decades of the $17^{\text {th }}$ century; the second aspect is geographical and demonstrates the importance of the basilica of St. Peter, its relics and its pilgrims in the early development of the cult of St. James and then, later, the connection between those hospitals and churches and the pilgrimage to the main Roman basilicas. To this is added a study of the works of art, preserved or lost, relics, processions and other liturgical expressions, completing a study which aims at presenting and overall picture of the subject.

Key words: Saint James the Great; Rome; Churches; Historical maps of Rome; Historical guides of Rome; Art; Cult; Iconography. 
El objetivo central de este artículo es la construcción de una topografía artística y devocional de Santiago el Mayor en Roma a partir del estudio de las iglesias y hospitales que estuvieron bajo su titularidad. Este criterio no impedirá que en numerosas ocasiones me refiera a capillas y altares situadas en otras iglesias y ligadas a la devoción privada al Apóstol, cuyo estudio exhaustivo espero afrontar en el futuro.

En un orden más amplio, espero que los resultados obtenidos podrán contribuir a esclarecer e interpretar la relación entre dos de los grandes centros de peregrinación de la cristiandad: Roma y Santiago de Compostela.

Para ofrecer esta primera visión conclusiva del culto jacobeo en la ciudad papal he partido de un primer trabajo sobre sus iglesias desaparecidas ${ }^{1}$, así como de algunas publicaciones dispersas sobre San Giacomo degli Spagnoli ${ }^{2}$, procediendo después a la consulta sistemática de las principales fuentes bibliográficas y documentales relativas a las iglesias bajo la advocación de Santiago, principalmente de las fuentes topográficas -catálogos y censos de iglesias, plantas históricas, guías de indulgencias y reliquias-e iconográficas.

El eje de nuestro discurso será cronológico. En primer lugar intentaremos fechar lo más aproximadamente posible la fundación, desaparición, derribo o cambio de titularidad de cada una de las iglesias. Paralelamente intentaremos aplicar un parámetro geográfico que nos permita establecer la disposición de todas ellas en el tejido urbano de la ciudad y sus accesos.

\section{Evolución del culto jacobeo en la ciudad de Roma}

Según las fuentes consultadas las primeras iglesias dedicadas a Santiago en la ciudad fueron las de San Giacomo Scossacavalli ${ }^{3}$ y San Giacomo alla Lungara ${ }^{4}$, ambas presentes en un censo vaticano de mediados del siglo $\mathrm{XI}^{5}$ y situadas en las inmediaciones de la basílica de San Pedro ${ }^{6}$. Una bula de Inocencio III (papa, 1198-1216) fechada en 1098 aporta la única referencia a una iglesia jacobea del siglo XII: una nueva mención a la iglesia de la Lungara7.

\footnotetext{
1 VÁzquez Santos, R., "Saint James in Rome: The Vanished Churches", en La Corónica, 36.6 Spring (2008), pp. 75-98.

2 VÁzquez SAntos, R., "San Giacomo degli Spagnoli en las guías de Roma y otras fuentes para la historia del arte", en Antológica Annua, 48 (2001), pp. 632-33; VÁzQuez SANTos, R., "Culto e iconografía jacobeos en la iglesia de San Giacomo degli Spagnoli”, en P. CAUCCI vON SAUCKEn (coord.): San Giacomo e l'Italia [Atti del Convengo Internazionale di Studi], Edizioni Compostellane, 2005, pp. 827-875; VÁzQuez SAntos, R., "La iglesia de San Giacomo degli Spagnoli a la luz del manuscrito 15449 del Archivio Storico Capitolino y otras fuentes del siglo XVII", en C. J. HERnANDO SÁNCHEZ (coord.): Roma y España. Un crisol de la cultura europea en la Edad Moderna, SEACEX, Madrid, 2007, vol. II, pp. 667-679.

${ }^{3}$ Llamada "Scossacavalli" o "del Borgo", se alzaba cerca del puente de Sant'Angelo, camino de la basílica de San Pedro, tal y como puede apreciarse en las plantas de Bufalini (1551), Duperac-Lafreri (1577) o Nolli (1748).

${ }^{4}$ Conocida como "in Settignana" en el pasado "per essere prossima alla porta Settimiana" (ARMELlinI, M.-CEChelli, C., Le chiese di Roma dal secolo IV al XIX, Roma, Nicola Ruffolo, 1942, v. II, p. 802). La iglesia aparece, además, en la reconstrucción de Hülsen de la Roma de los siglos IV-XV (HÜLSEN, C., Le chiese di Roma nel Medio Evo: cataloghi ed appunti, Firenze 1927) y en las plantas históricas de Bufalini (1551), Du Pérac (1577), Tempesta (1593), Maggi (1625) y Nolli (1748).

5 ERHLE, F., Ricerche su alcune antiche chiese del Borgo di San Pietro, Roma, Tipografía Vaticana, 1907, p. 40.

${ }^{6}$ La iglesia de Scossacavalli estaba en el rione XIV de Roma, Borgo, "nel mezzo de la via di san Pietro e castello sancto Angelo" (Indulgentie \& Reliquie de le chiese di Roma, f. Hr). La iglesia de Lungara se alza todavía en el "rione" XIII o de Trastevere.

${ }^{7}$ La bula recoge la concesión de la iglesia al capítulo de San Pedro y fue confirmada por Gregorio IX (1227-41) en 1228 (HüLSEN, C., op. cit., p. 268).
} 


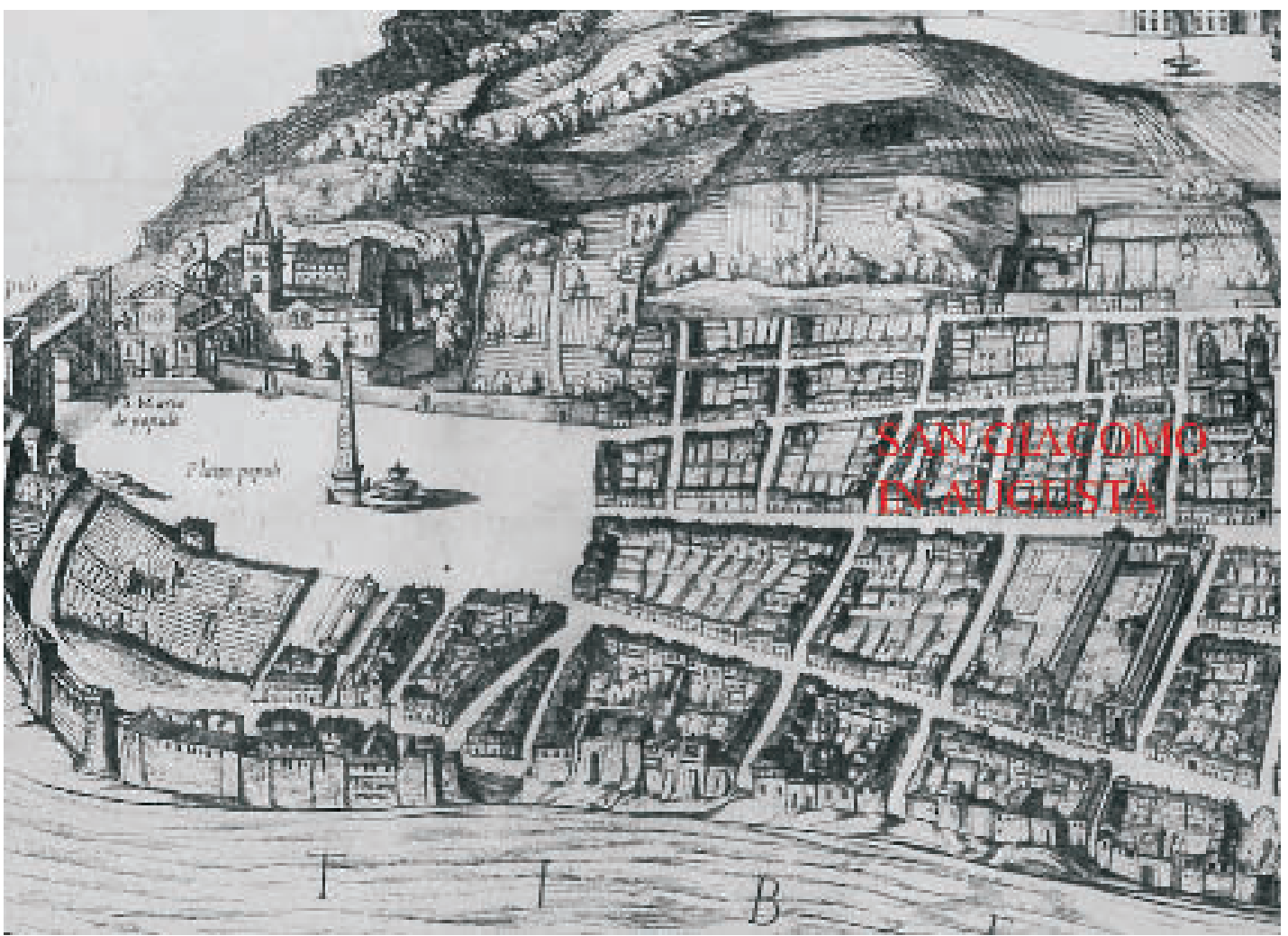

Fig. 1. San Giacomo in Augusta. Detalle de la planta de Roma de Antonio Tempesta. 1593.

En el siglo XIII tenemos noticia de dos nuevas iglesias: San Giacomo in Horrea, situada en la zona del Aventino ${ }^{8}$ y citada por el catálogo Parigino (c. 1230) ${ }^{9}$, y San Giacomo degli Armeni, que se alzaba en el Borgo o inmediaciones de San Pedro ${ }^{10}$ y aparece documentada en una inscripción conservada en San Juan de Letrán fechada en $1240^{11}$.

Casi de forma inmediata a la institución del jubileo romano tenemos noticia de la existencia de otra iglesia en la zona del Aventino: San Giacomo d'Altopascio ${ }^{12}$. Aparece citada en una bula de $1302^{13}$, así como en la documentación de la Orden de

8 Ausente de las plantas de Roma pero fácilmente situable en la "Regio Horrea” que en la Edad Media: “... comprendeva la pianura sotto l'Aventino sino alla ripa del Tevere ed il Monte Testacci” (HülsEn, C., op. cit., p. 266).

9 Hülsen, C., op. cit., p. 266; Valentini, R.-Zucchetti, G., Codice topográfico della Città di Roma, Roma, Tipografia del Senato, 1946, vol. III, p. 286.

10 Se alzaba en las faldas de la colina del Santo Spirito, o del Palazzolo, al sur de San Pedro, tal y como aparece en la planta II de Borgatti (Borgatti), M., Borgo e S. Pietro nel 1300, nel 1600 e nel 1925, Roma, Federico Punset, p. 49 y tav. II).

${ }^{11}$ La lápida reapareció en 1660, se custodia en el Museo Lateranense y posee una breve inscripción: "San Petri porticu e poenitentiaria vetere" (HüLSEN, C., op. cit., p. 264).

${ }^{12}$ Se hallaba muy cerca del lugar en el que hoy se alza Sant'Eligio dei Ferrari. Aparece en los catálogos de Torino (c. 1320) y Signorili (c. 1425)

${ }^{13}$ La bula de Bonifacio VIII (1294-1303) refiere la concesión a Giono de Alonis de Prato de la "rectoria Hospitalis S. Jacobi, siti in contrada que dicitur Cortina parva de Urbe, ad hospitale sancti Jacobi de Altipassu Lucanae diocesis pertinentis" (HÜLSEN, C., op. cit., p. 264). 


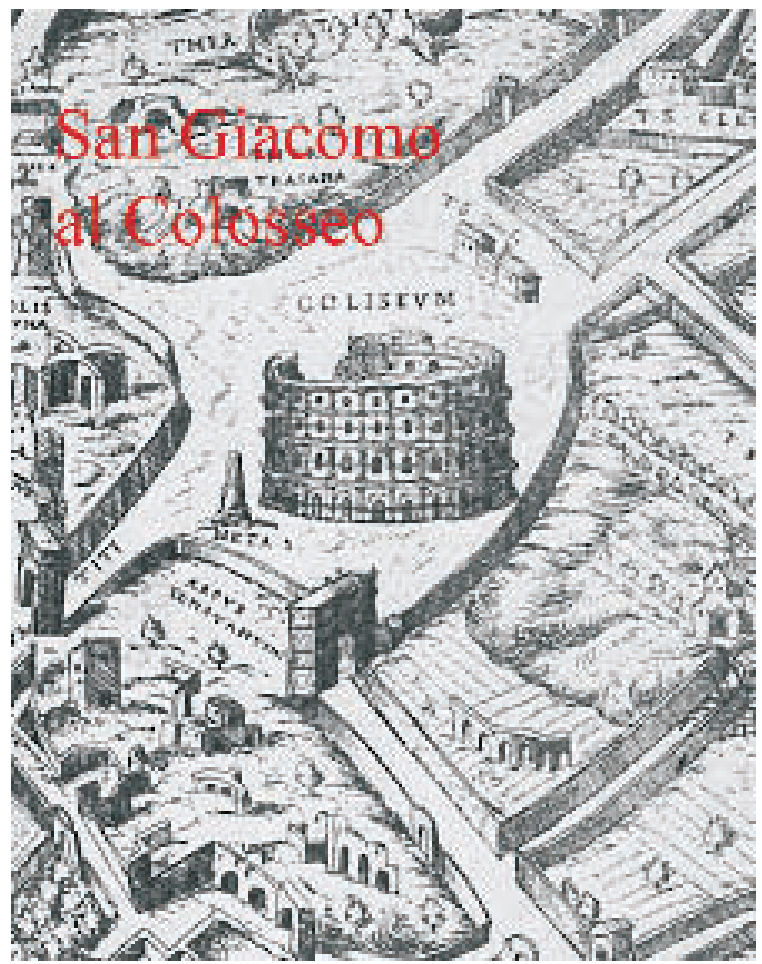

Fig. 2. San Giacomo al Colosseo. Detalle de la planta de Roma de Francesco de Paoli. 1623.

Altopascio, que fue responsable de su restauración y la dotó de un hospital dedicado a Santiago ${ }^{14}$.

En los años sucesivos la fundación de otras iglesias con sus respectivos hospitales de titularidad jacobea confirma la tendencia de aumento de culto a Santiago en la ciudad. Hacia 1320 el catálogo de Torino incluye la iglesia y hospital de San Giacomo in Thermis ${ }^{15}$, que se alzaba en el "rione" Sant'Eustacchio", así como la iglesia de San Giacomo al Lago" mura" dedicada al Apóstol ${ }^{18}$.

Pocos años después, hacia 1338, se produjo la fundación del hospital de San Giacomo in Augusta (fig. 1), que tomó su nombre del cercano mausoleo imperial ${ }^{19}$. Sin abandonar el

14 VÁzquez Santos, R., "Santiago en Roma I: El desaparecido hospital de San Giacomo de Altopascio y el cuadro de altar de Sciolante da Sermoneta", en Compostellanum, L (2005), pp. 671-679.

15 "Hospitale sancti Jacobi de Termis habet V servitores" (HÜlsEn, C., op. cit., p. 29).

16 Se alzaba junto a las ruinas de las termas de Nerón, cerca de la Platea Lombarda, actual Piazza Madama, por lo que en ocasiones aparece citada como: "S. Iacobi(in Thermis) Lombardorum" (ARMELlni, M., Le chiese di Roma dal secolo IV al XIX, ed. a cura di Carlo Cecchelli, Roma, 1942, v. I, pp. 535-536).

17 "Ecclesia sancti Jacobi de Lacu non habet servitorem" (HüLSEN, C., op. cit., p. 38).

${ }^{18}$ La planta de Bufalini (1551) permite situarla más allá de la puerta de S. Giovanni, en un cruce de la Appia nueva y la Tuscolana.

19 Presente en casi todas las plantas de Roma, la iglesia se alza todavía cerca del mausoleo de Augusto. Desde el siglo XVI pasó a denominarse "degli Incurabili" y actualmente es conocida como al "Corso". Forcella reproduce un fragmento de su inscripción fundacional de 1338, conservada en el patio del hospital, que completa a partir de la obra 


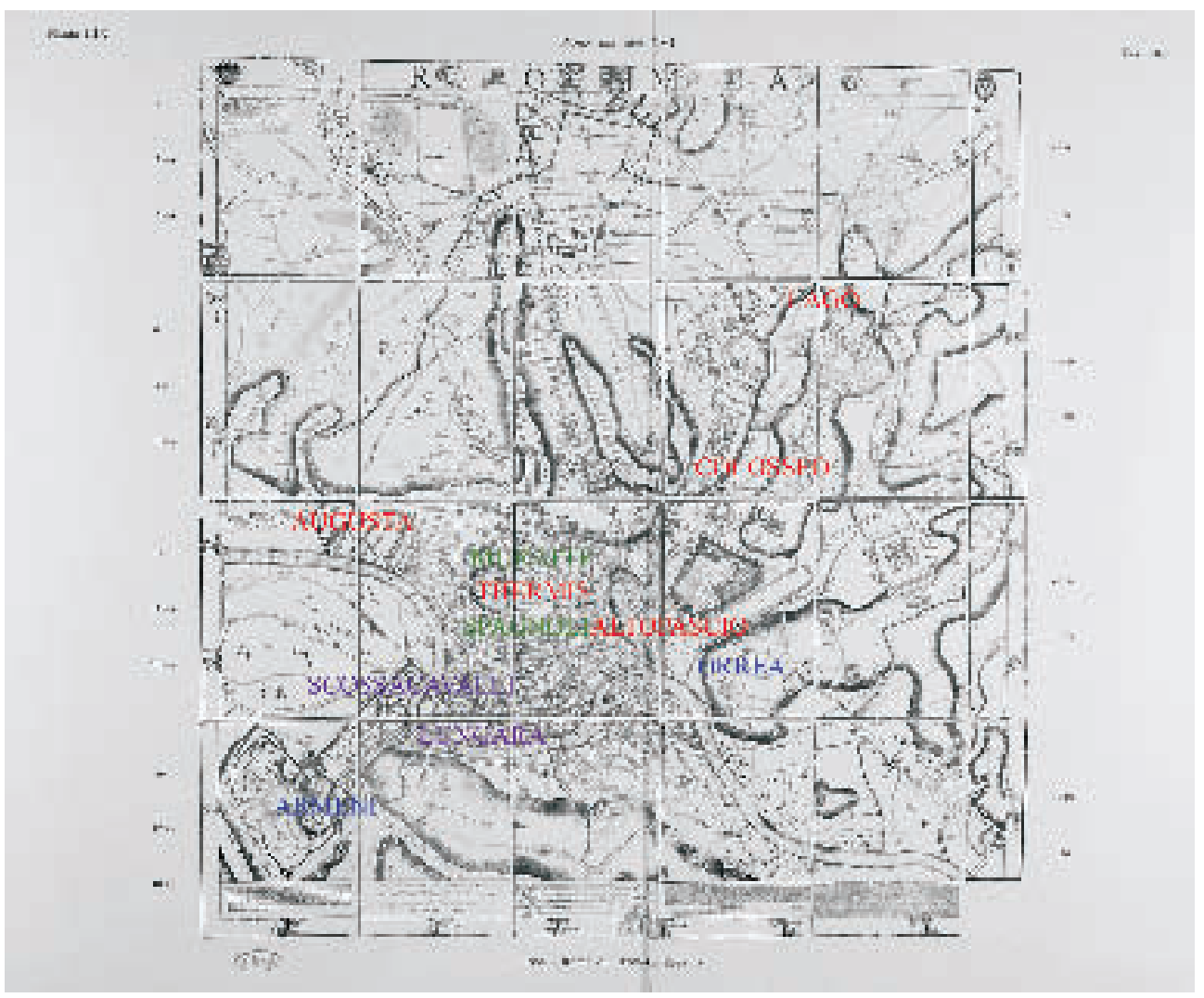

Fig. 3. Iglesias dedicadas a Santiago en la ciudad de Roma superpuestas a la planta de Roma de Leonardo Bufalini (1551).

siglo XIV, en 1383 un pergamino conservado en el archivo de Letrán se refiere al hospital e iglesia de San Giacomo al Colosseo ${ }^{20}$ (fig. 2), que se hallaba junto al célebre monumento romano, en uno de los accesos a la basílica de San Juan ${ }^{21}$.

El catálogo de Signorili (c. 1425) refleja la situación del culto jacobeo a comienzos del siglo $\mathrm{XV}^{22}$. En el catálogo figuran varias iglesias apenas fundadas, como las ya citadas de Augusta y Colosseo, compareciendo además por vez primera la de San Giacomo alle Muratte, fundada por Lorenzo Musciani en las cercanías de la fontana de Trevi a finales del siglo XIV ${ }^{23}$ y gestionada por el hospital de Sancta Sanctorum ${ }^{24}$.

de Galletti (Forcella, V., Iscrizioni delle chiese e d'altri edifici di Roma. Dal secolo XI fino ai giorni nostri, Roma, 1869-84, IX, p. 127, n. $\left.{ }^{\circ} 244\right)$.

20 Armellini, M., op. cit., I, p. 183; HÜLSEN, C., op. cit., p. 265.

${ }^{21}$ La iglesia se alzaba al final de la vía de San Giovanni, entre las iglesias de Letrán y los SS. Quattro Coronati. Se distingue claramente en las plantas de Bufalini (1551), Du Pérac (1577), Francesco de Paoli (1623) y Giovanni Battista Nolli (1748).

${ }^{22}$ Las referencias han sido reproducidas por Hülsen (HÜLSEN, C., op. cit., pp. 46-51).

${ }^{23}$ Su situación puede identificarse a través de la reconstrucción de Cristiano Hülsen (1926) y las plantas de Bufalini (1551) y Du Pérac (1577).

${ }^{24}$ Cfr. Armellini, M., op. cit., I, p. 351; HÜLsEn, C., op. cit., p. 267; Lombardi, F., Roma, le chiese scomparse. La memoria storica della città, Roma, Fratelli Palombi Editori, 1996, p. 119. 


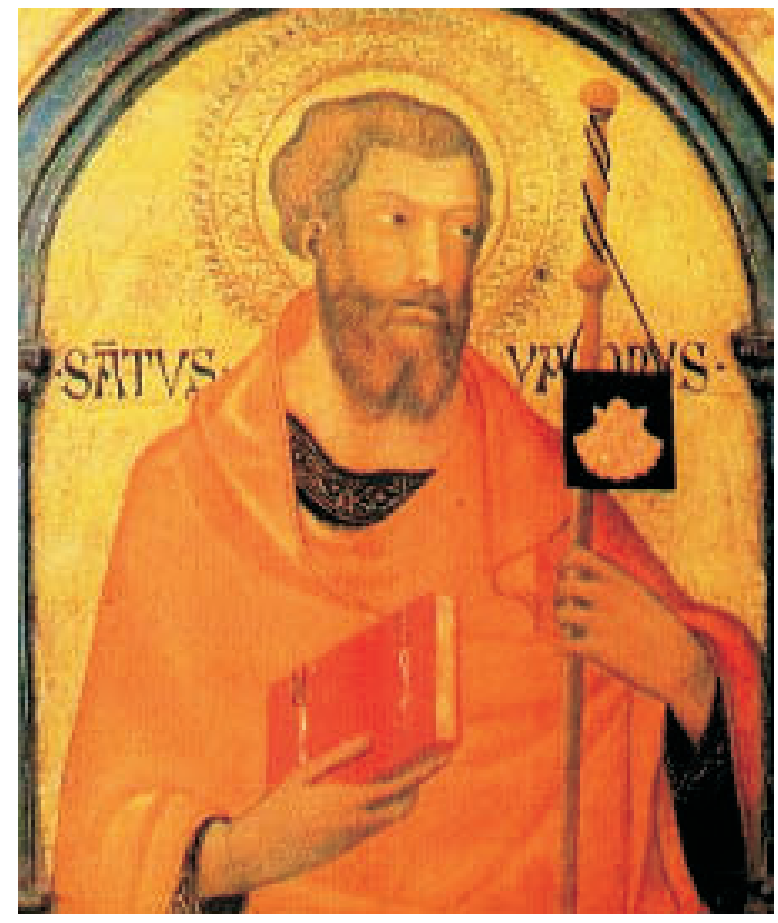

Fig. 4. Simone Martini. San Giacomo Maggiore. Città del Vaticano. San Giovanni in Laterano.
La única novedad posterior será la fundación de la iglesia y hospitales de San Giacomo degli Spagnoli en la plaza Navona ${ }^{25}$, fundación que suele fecharse en torno al jubileo de $1450^{26}$ y que comparece por vez primera en los catálogos romanos en un libro de la Compagnia del Gonfalone de $1470^{27}$.

A finales del siglo $\mathrm{XV}$ podemos establecer un punto de inflexión en la evolución del culto pues, desde entonces, asistiremos a la paulatina desaparición de las iglesias jacobeas de Roma (fig. 3).

El catálogo del Vaticano fechado en 1492, el de 1555 conocido como "Tassa" de Pío IV (papa, 1560-65) y el muy extenso de Pío V (papa, 156672 ), fechado en 1566 , confirman con sus repetidas omisiones la desaparición de las iglesias del $\mathrm{Lago}^{28}$, Thermis ${ }^{29} \mathrm{y}$ $\mathrm{Orrea}^{30}$. Por su parte, la omisión de San Giacomo di Altopascio en el Anónimo Spagnolo (c. 1570) confirma su derribo en $1561^{31}$. La iglesia de los armenios parece haber corrido la misma suerte 32 .

La situación a finales del siglo XVI nos la dan dos catálogos: el conocido como Anónimo Spagnolo (c. 1570) y el muy detallado de Francesco del Sodo (1575-83). En ambos comparecen las iglesias de la Lungara, Scossacavalli,

${ }^{25}$ La iglesia y su hospital masculino ocuparon esta ubicación desde su fundación mientras que el hospital femenino ocupó diversas edificaciones a lo largo de su historia.

26 Tradicionalmente se ha fechado siguiendo la inscripción relativa a su fundador, el obispo Alfonso de Paradinas, que se disponía en el arquitrabe de la puerta principal (ForCELLA, V., op. cit., vol. I, p. 504), algunas novedades documentales podrían adelantarla al año 1440 (VÁzQUEZ SANTOS, R., op. cit., 2007, p. 668).

27 HüLSEN, C., op. cit., p. 61.

${ }^{28}$ La planta de Bufalini (1551) constituye el último testimonio sobre la iglesia.

${ }^{29}$ La última noticia que conocemos se refiere a su concesión en 1478 a la abadía de Farfa, futura San Luigi dei Francesi (ARMELlini, M., op. cit., II, p. 1301).

${ }^{30}$ La iglesia desaparece de la documentación en la segunda mitad del XV. Aunque existe una referencia a " $S$. Iacobo al Monte Aventino" en el catálogo de Pío V (1566-1572) (cfr. HüLSEN, C., op. cit., p. 104), creemos que se trata de una alusión al lugar, pues según recoge Lanciani el nombre de la iglesia permaneció como topónimo (LANCIANI, R., Storia degli scavi di Roma e notizie intorno le collezioni romane di antichità, Roma, Loescher, 1907, III, p. 175).

${ }^{31}$ La iglesia había pasado a depender de la universidad y cofradía de los herreros, quienes en 1561 encargaron su demolición al constructor Calvanis con el fin de edificar una nueva iglesia dedicada a su patrón san Eloy (L'Arciconfraternitá di S. Eligio de' Ferrari e la sua chiesa di S. Eligio in Roma, Roma, Arciconfraternitá di S. Eligio de' Ferrari, 1998).

32 Borgatti la identifica con la iglesia de "S. Jacobo nel giardino già del Flisco", citada en el catálogo de Pío V (1566-1572) que, según nuestra opinión, se refiere a la cercana de Scossacavalli (BorGATTI, M., op. cit., p. 50). 


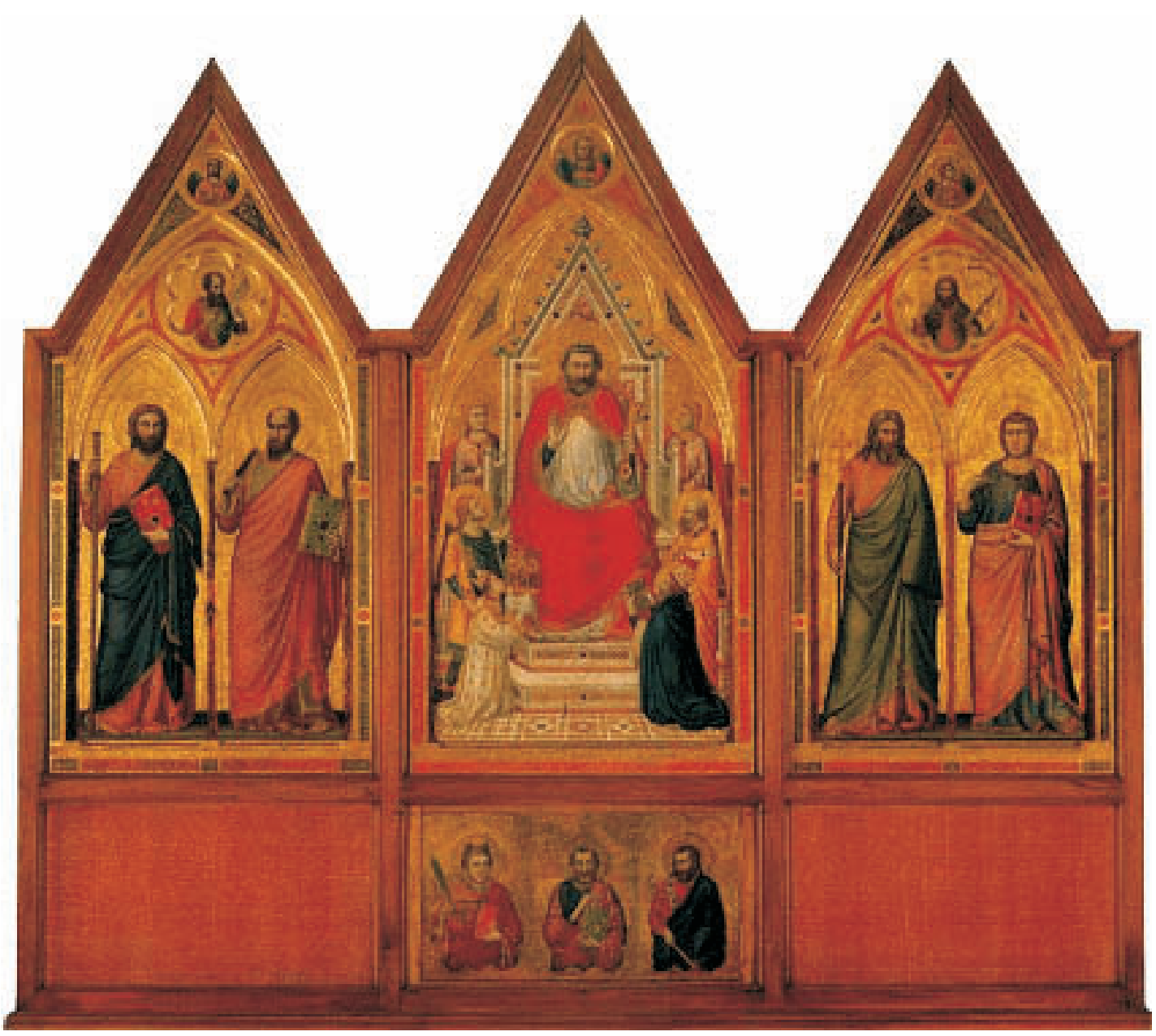

Fig. 5. Giotto. Polittico Stefaneschi. c. 1330. Città del Vaticano. Pinacoteca Vaticana.

Muratte, Augusta, Colosseo y Spagnoli33. Esta realidad se mantendrá a lo largo de la primera mitad del siglo XVII hasta que, tras un incendio ocurrido en 1643, desaparecerá también la iglesia de Muratte $^{34}$.

${ }^{33}$ Hülsen reproduce el texto de los dos catálogos, cuyas alusiones a iglesias y hospitales con la titularidad de S. Iacobi son fácilmente identificables gracias a las descripciones y al orden geográfico seguido por ambos (HÜLSEN, C., op. cit., pp. 107-114, 115-122).

34 "Nel 1643 il dì 26 di Gennaro il fuoco appresovi, dannegiò in gran maniera questo sacro luogo" (TORRIGIO, F. M., Historica Narratione della chiesa Parocchiale et Archiconfraternità di Christo posto in San Giacomo Apostolo in Borgo, Roma, Grignani, 1649, p. 152). 

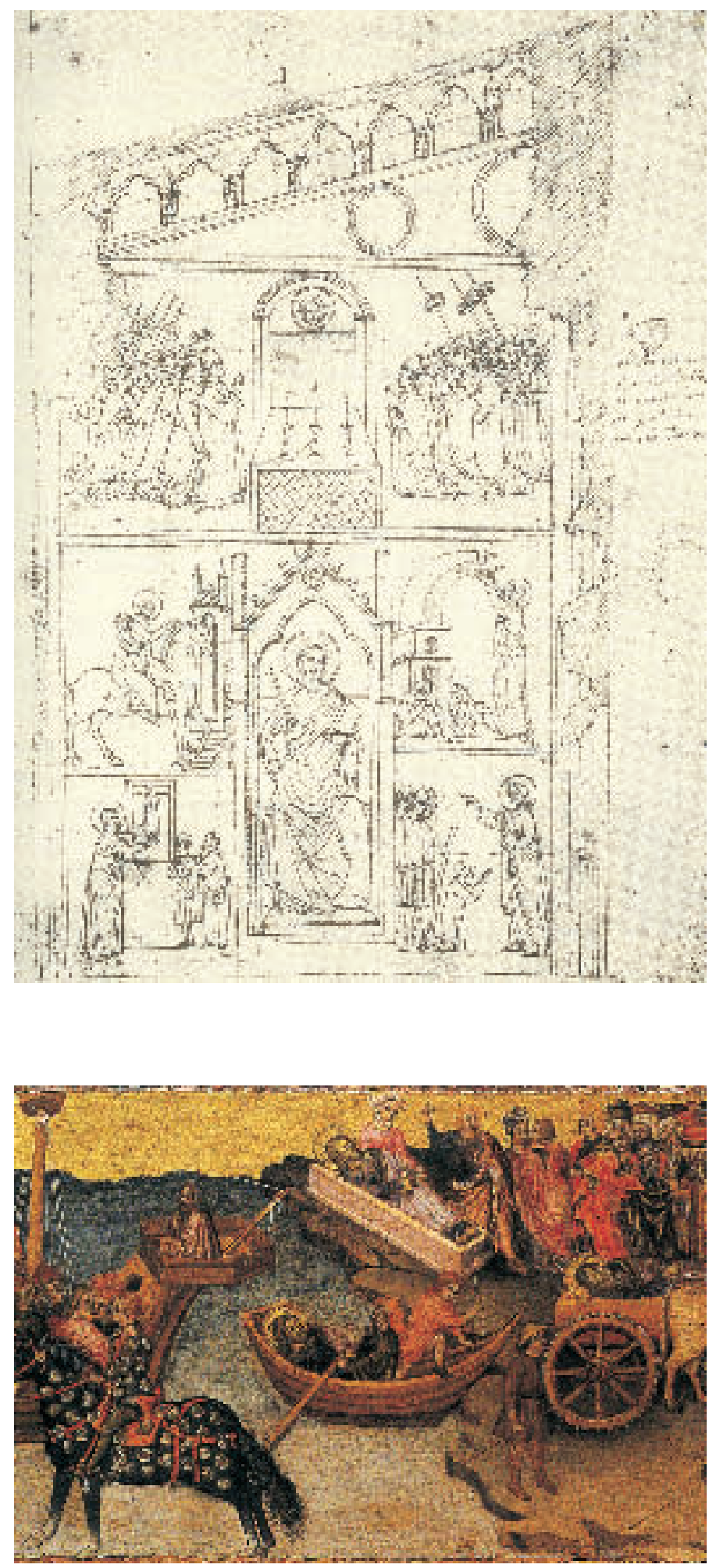

Fig. 6. Séroux d'Angicourt.

Dibujo de los frescos desaparecidos de San Giacomo al Colosseo. FECHA. Città del Vaticano.

Biblioteca Apostólica Vaticana, Vat. Lat. 9848 , f. 13v.
Fig. 7. Giovenale di Orvieto. Milagros de Santiago el Mayor. 1441. Museo Diocesano de Camerino. Procedente de la iglesia de Santa Maria Araceli de Roma. 


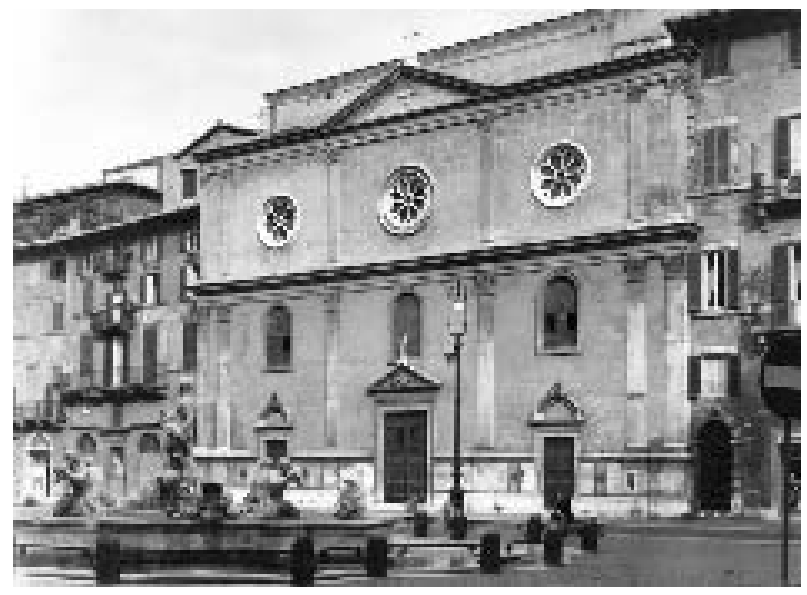

Fig. 8. Fachada del Sacro Cuore (antigua iglesia de San Giacomo degli Spagnoli).

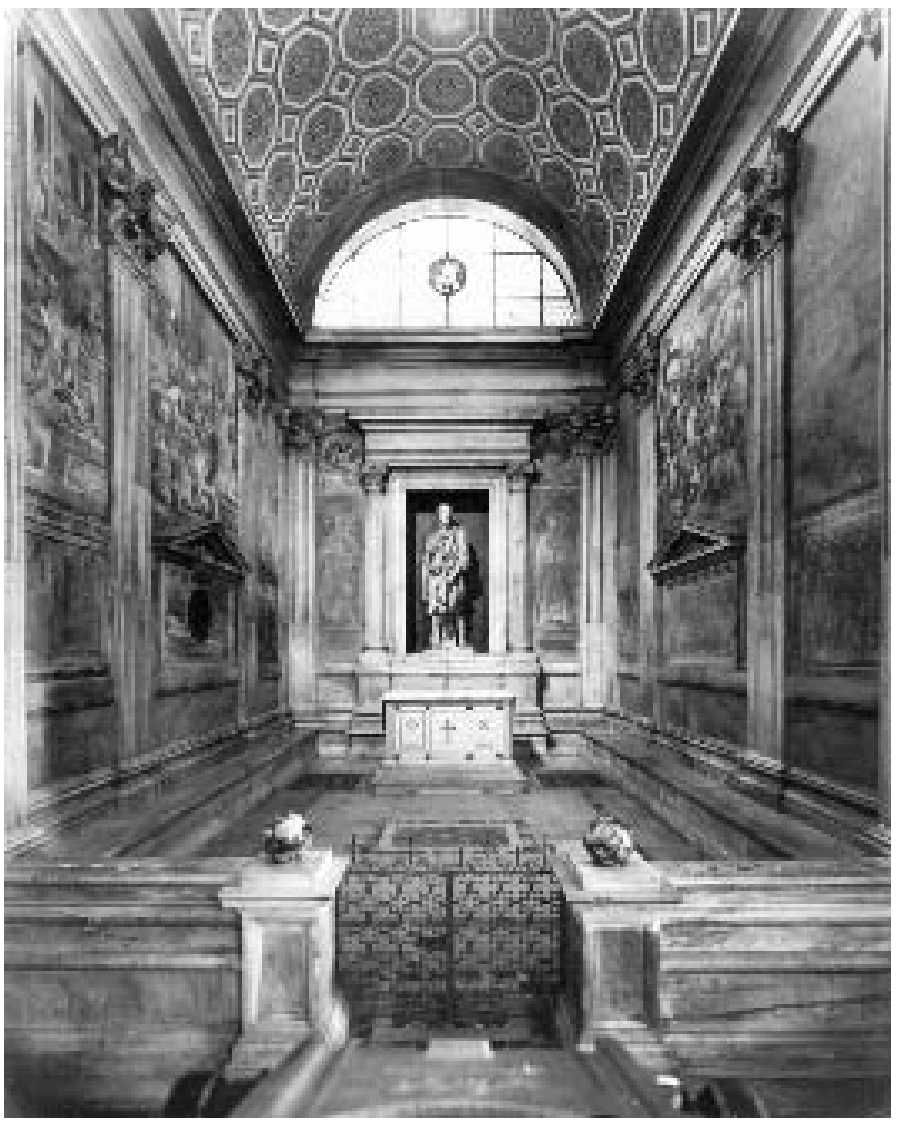

Fig. 9. Antonio da Sangallo, Jacopo Sansovino, Pellegrino da Modena. Capilla de Santiago o del cardenal Serra. c. 1517. Roma. Sacro Cuore (antigua iglesia de San Giacomo degli Spagnoli). 


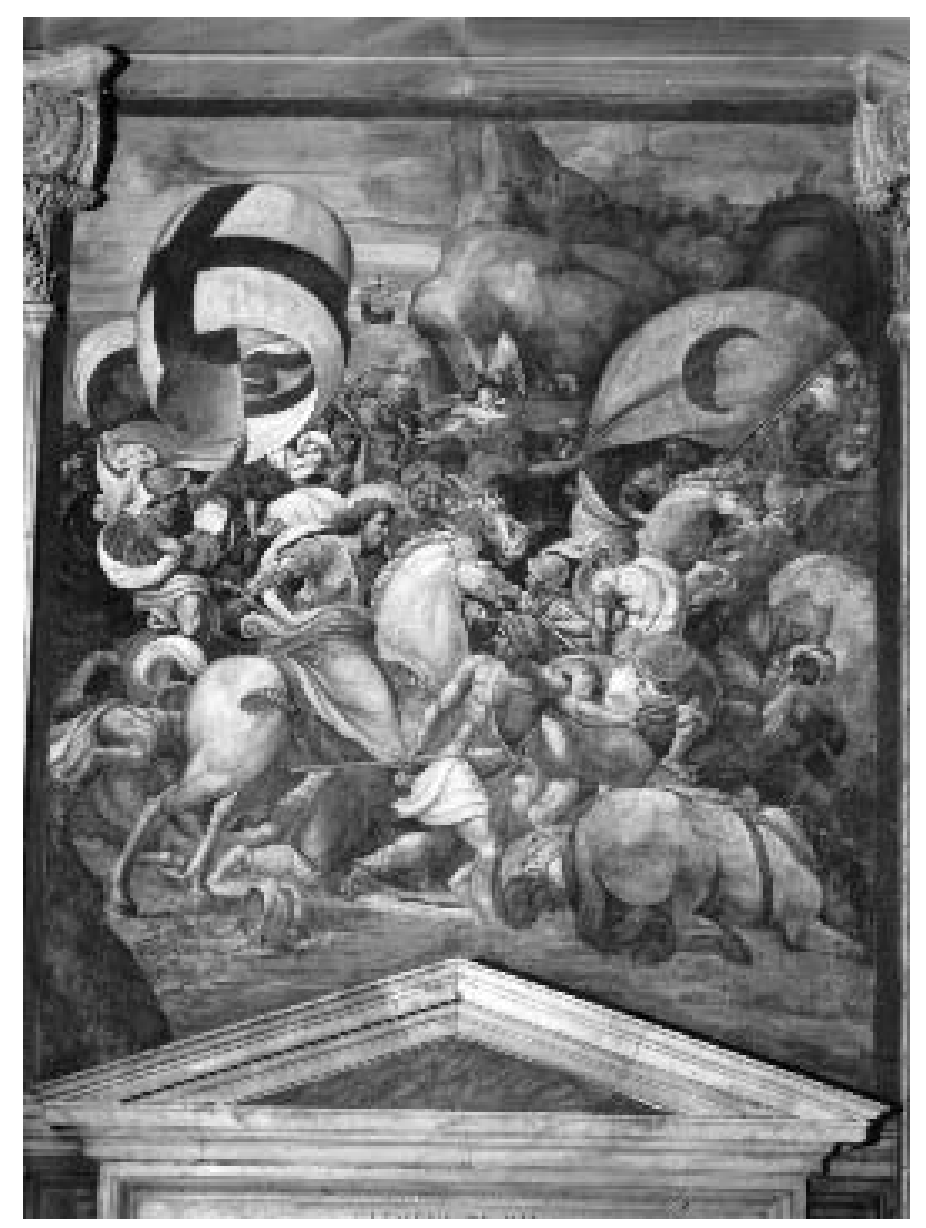

Fig. 10. Pellegrino da Modena. Batalla de Clavijo. c. 1517. Roma. Sacro Cuore (antigua iglesia de San Giacomo degli Spagnoli).

Origen y expansión del culto: Santiago como patrón de peregrinos y peregrinaciones

El análisis de los datos reproducidos deja ver que las primeras iglesias dedicadas al hijo del Zedebeo nacieron en torno a las basílicas de San Pedro (Scossacavalli, Armeni), San Juan de Letrán (Orrea) y sus accesos (Lungara), probablemente ligadas al fenómeno de la peregrinación a Roma y con un carácter marcadamente hospitalario. Todo parece confirmar que la devoción al Santo en Roma se debió desde el comienzo a la peregrinación compostelana. El culto individual a un Apóstol cuyas reliquias no se custodiaban en la ciudad parece muy improbable y, por otro lado, no podemos dejar de notar la coincidencia de fechas entre las primeras referencias jacobeas de Roma y el traslado de la sede de Iria a Compostela con el consecuente nacimiento de la Iglesia de Santiago como tal ${ }^{35}$. Todo parece evidenciar que la peregrinación a Compostela y el

35 LóPEZ Alsina, F., "Urbano II y el traslado de la sede episcopal de Iria a Compostela", en El Papado, la Iglesia Leonesa y la Basílica de Santiago a finales del siglo XI. El traslado de la Sede Episcopal de Iria a Compostela en 1095, Santiago de Compostela, 1999, pp. 107-127. 


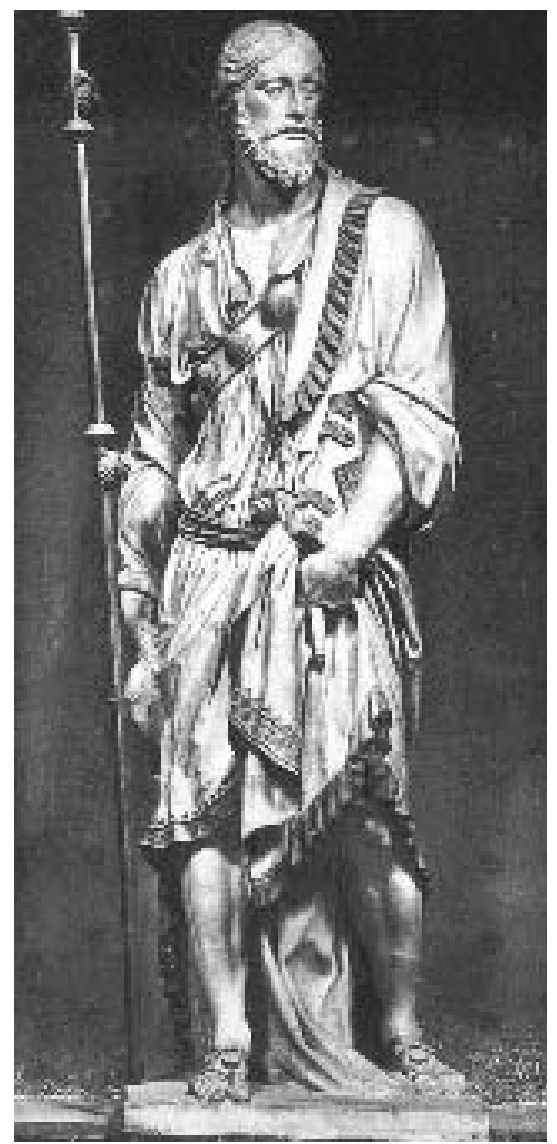

Fig. 11. Jacopo Sansovino. Santiago el Mayor. c. 1517. Roma. Santa María de Monserrato. Procedente de la antigua iglesia de San Giacomo degli Spagnoli.

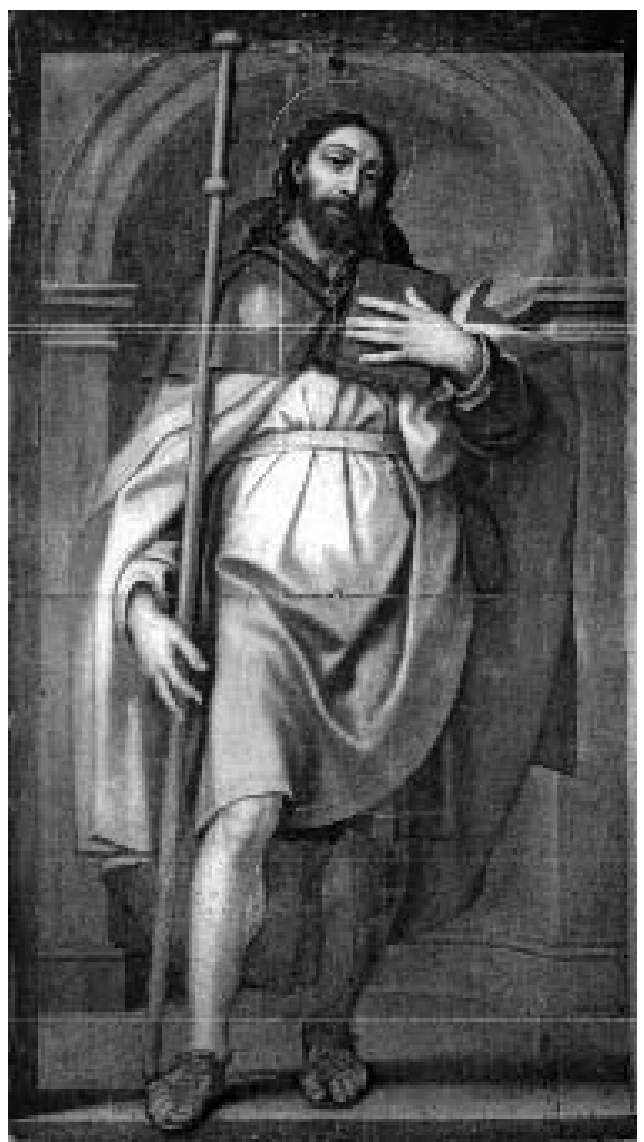

Fig. 12. Marcello Venusti. Santiago el Mayor. Segundo tercio del siglo XVI. Roma. Santa María sopra Minerva.

patronazgo de Santiago sobre los peregrinos fueron los verdaderos responsables del origen de su culto, e incluso de su desarrollo durante los primeros siglos del jubileo romano.

Entre los factores históricos determinantes hay que subrayar la labor de algunos personajes concretos -Diego Gelmírez (arzobispo, 1100-1139), Urbano II (papa, 1088-99) y Calixto II (papa, 1119-1124)- así como las consecuencias del extraordinario ascenso de la iglesia compostelana y la peregrinación a Santiago en los siglos XII y XIII. La figura de Diego Gelmírez tiene un protagonismo particular pues su donación de "Il braccio di S. Iacopo Maggiore" a la romana iglesia de San Crisogono in Trastevere ${ }^{36}$, dio lugar a un nuevo culto a las reliquias y propició la introducción de un tema iconográfico hasta entonces inédito en Roma: la "Traslatio" del Apóstol ${ }^{37}$.

\footnotetext{
${ }^{36}$ CastiñeIras GonzÁlez, M. A., "Calixto II, Giovanni da Crema y Gelmírez”, en Compostellanum, XLVII (2002), p. 404.

37 Manuel Castiñeiras reproduce una descripción de Mancini de la pintura, atribuida a un pintor de nombre Giovanii (CASTIÑEIRAS GonZÁLEZ, M. A., op. cit., p. 403). La donación de la reliquia compostelana y su repercusión en el
} 
Otro aspecto fundamental fue la difusión de los principales textos hagiográficos. En primer lugar el Codex Calixtinus ${ }^{38}$, sobre todo su segundo libro o Liber Miracolorum, así como sus posteriores derivaciones o Libellus $^{39}$, textos fundamentales en la elaboración de la figura del santo patrón y protector de peregrinos ${ }^{40}$. Esta difusión se produjo de forma muy temprana en Italia, sobre todo gracias a Pistoia, ciudad cercana a la via Francigena convertida en "rocca forte" del culto jacobeo a partir de la donación de una reliquia del Apóstol por el arzobispo Diego Gelmírez. A mediados del siglo XIII la catedral de Pistoia poseía ya dos manuscritos o copias parciales del Códice Calixtino, así como de la correspondencia mantenida en el siglo XII entre Atón de Pistoia (obispo, 1134-1153) y el citado Diego Gelmírez, documentos a los que posteriormente se sumarían sendas copias de los siglos XV y XVII ${ }^{41}$.

Posteriormente la redacción de legendarios como la Legenda aurea de Jacopo Varazze, contribuyeron decisivamente a la creación de un corpus iconográfico estandarizado y cristalizado que se repetirá en toda Italia a lo largo de los siglos XIV y XV, de la mano de los dominicos pero también de los agustinos, conocidos en Italia como Eremitani, que difundieron el culto jacobeo desde sus conventos de Padua o Bolonia. En este sentido es particularmente interesante la iconografía del convento de San Giacomo de Bolonia, que en el siglo XIV denota un conocimiento de las fuentes compostelanas en obras como la batalla de Clavijo atribuida al "Maestro della Corcefissione Campana"42.

Las consecuencias del proceso descrito son evidentes en Italia hacia el año 1300, cuando las principales fuentes literarias señalan a Santiago como patrón de los peregrinos. Sirvan como ejemplo dos célebres obras de Dante, en las que el poeta celebra al Apóstol y su peregrinación: la Vita Nova ${ }^{43}$ y la Divina Commedia ${ }^{44}$.

Roma no se mantuvo ajena al discurso apenas expuesto pues, como hemos visto, experimentó un enorme auge del culto jacobeo a lo largo de todo el siglo XIV. Así pues con el nacimiento del

arte y culto jacobeo, serán tratados en profundidad en el libro-catálogo "Compostela y Europa. La historia de Diego Gelmírez" que la S. A. de Xestión do Plan Xacobeo publicará el próximo año 2010.

${ }^{38}$ La crítica coincide en señalar al Códice Calixtino como la respuesta a las carencias del culto y ceremonial litúrgico jacobeo (Díaz y Díaz, M. C., El Códice Calixtino de la Catedral de Santiago. Estudio codicológico y de contenido, Santiago de Compostela, 1998, pp. 25-26).

${ }^{39}$ Formas reducidas del Calixtino que incluían los textos relativos a la Traslatio y a los milagros, difundidas por toda Europa desde mediados del siglo XII (DíAz Y DíAz, M. C., op. cit., pp. 38-42).

${ }^{40}$ Véase: Herbers, K., “The Miracles of St. James”, en J. Williams-A. Stones (coords.): The Codex Calixtinus and the Shrine of St. James, Jakobus-Studien 3, Tübingen, 1992, pp. 11-35; Herbers, K., "Mentalidad y milagro. Protagonistas, autores y lectores", en Compostellanum, XL (1995), pp. 321-338.

41 Véase: Gai, L., Manno Tolu, R., Savino, G., L'Apostolo San Jacopo in documenti dell'Archivio di Stato di Pistoia, Pistoia, 1985; GAI, L., "Testimonianze jacobee e riferimenti compostellani nella storia di Pistoia dei secoli XII-XIII", en Pistoia e il Cammino di Santiago. Una dimensione europea nella Toscana medioevale [Atti del Convegno Internazionale, Pistoia 28-29-30 settembre 1984], Edizioni Scientifiche Italiane, Perugia, 1987, pp. 119-230.

42 Medica, M., "Un secolo d'arte a San Giacomo Maggiore", en G. Benevolo-M. Medica, I Corali di San Giacomo Maggiore. Miniatura e committenti nel Trecento, Musei Civili d'Arte Antica. Monografie, Edisai Edizioni, Bologna, 2003, pp. 37-39.

43 "E dissi 'peregrini' secondo la larga significatione del vocabolo, ché peregrini si possono intendere in due modi, in uno largo e in uno strecto: in largo, in quanto è peregrino chiunque è fuori della sua patria; in modo strecto non s'intende peregrino se non chi va verso la Casa di Sa' Iacopo o riede. E però è da sapere che in tre modi si chiamano propriemente le genti che vanno al servigio dell'Altissimo: chiamansi palmeri in quanto vanno Oltremare, là onde molte volte recano la palma; chiamansi peregrini in quanto vanno alla Casa di Galitia, però chela sepultura di Sa' Iacopo fue più lontana dalla sua patria che d'alcuno altro apostolo; chiamansi romei in quanto vanno a Roma, là ove questi cu' io chiamo peregrini andavano" (DANTE AlighIERI, Vita Nova, XL, 6-7).

44 "e la mia donna, piena di letizia, / mi disse: "mira, mira: ecco il barone / per cui là giù si visita Galizia" (Dante AlighIERI, Divina Commedia, Paradiso, XXV, 16-18). 
jubileo romano se produce una situación paradójica: la ciudad que reivindica el papel de principal centro de peregrinación de la Cristiandad, acepta y asume el patronazgo de Santiago, cabeza de su principal competidora, sobre sus propios peregrinos ${ }^{45}$.

La contrapartida visual nos la dan numerosos ejemplos iconográficos de Santiago "peregrino" representado en la Roma del jubileo por sus dos pintores más célebres: Simone Martini (c. 1284-c. 1344) y Giotto (c. 1267-1337). Una tabla pintada por el sienés para San Juan de Letrán muestra al Santo portando su escarcela ornada con una concha (fig. 4), alejándolo del resto de los apóstoles tal y como ya había hecho en la Maestà del Palacio Público de Siena, donde una "venera" distinguía a Santiago de los anónimos santos y apóstoles que se apiñan a la izquierda de la Virgen. Más significativo es todavía el célebre políptico de Giotto conocido por el nombre de su mecenas, el célebre Jacopo Stefaneschi (cardenal, 1295-1343), una de las obras de arte más importantes del papado de Bonifacio VIII (papa, 1294-1303) en la que Santiago, con bordón y escarcela, comparte protagonismo con san Pedro (fig. 5) ${ }^{46}$. La comparecencia del Apóstol en el altar Stefaneschi podría explicarse simplemente por ser Jacopo el nombre de bautismo del cardenal, pero también este hecho debe ser interpretado como signo de la importancia alcanzada por el culto jacobeo en la ciudad, pues el nombre de Santiago empezó a aparecer en las principales familias romanas sólo a partir de las últimas décadas del siglo XIII ${ }^{47}$. Un ejemplo muy elocuente de esa devoción privada nos lo ofrece la familia Colonna, a cuyo mecenazgo se debió la fundación del hospital de San Giacomo in Augusta en $1338^{48}$.

En las últimas décadas del siglo XIV, cuando los conflictos del cisma transformaron el jubileo romano en un instrumento político con convocatorias especiales en 1390 y 1400, encontramos el primer ciclo iconográfico jacobeo de la ciudad: los frescos de San Giacomo al Colosseo (fig. 6). Las pinturas de tamaño monumental ilustraban la leyenda y milagros del Santo en la contra-fachada de la iglesia hasta su derribo en el siglo XIX. A pesar de su pérdida podemos reconstruirlas gracias a la existencia de tres copias: las acuarelas encargadas por Francesco Barberini (cardenal, 1645-1679) hacia 1635"49; una obra comisionada por Séroux d'Agincourt (1730-1814) a finales del siglo XVIII ${ }^{50}$; y las acuarelas realizadas por Ferdinando Boudard $(1760-1825)^{51}$. Entre las

\footnotetext{
45 Es importante recordar las reivindicaciones de Roma a pesar de que la crítica tiende, cada vez más, a ver el jubileo romano de 1300 como un suceso casi espontáneo más que como el fruto de un proyecto político del papado: "Con il giubileo, Roma fini con l'occupare definitivamente quel posto centrale nell'immaginario e nel sistema giuridico e sacrale della chiesa latina che fino ad allora era spettato a Gerusalemme" (CARDINI, F., "Fallimento della crociata in Terrasanta, nàscita del giubileo. L'eclisse di Gerusalemme", en Strinati, C., Cardini, F., Fagiolo, M., Le GofF, J., Morello, G. (coords.): La Storia dei Giubilei, vol. I (1300-1423), BNL Edizioni, Roma, 1997, pp. 65-66.

${ }_{46}$ Sobre la importancia de la obra de Giotto y del cardenal Stefaneschi en el contexto del Jubileo de 1300 véanse Kessler, H. L., Zacharias, J., Rome 1300. On the path of the pilgrimage, Yale University Press, New Haven and London, 2000; Romanini, A. M. (coord.): Roma Anno 1300 [Atti della IV Settimana di Studi di Storia dell'Arte Medievale dell'Università di Roma "La Sapienza" (19-24 maggio 1980)], Roma, 1983; Strinati, C., CARDini, F., FAGIOLO, M., Le Goff, J., Morello, G. (coords.): op. cit., vol. I (1300-1423), BNL Edizioni, Roma, 1997.

${ }^{47}$ El culto a Santiago en la familia Stefaneschi, una de las principales de Roma desde el siglo X, aparece en el siglo XIII cuando tenemos noticias de la existencia de un "Jacopo" antepasado del cardenal, así como de una sepultura de la familia en San Giacomo alla Lungara (Marchetti Longhi, G., Gli Stefaneschi [Le grandi famiglie romane, IX], Istituto di Studi Romani Editore, Roma, 1954, pp. 51-52).

${ }^{48} \mathrm{El}$ nombre de Santiago no fue utilizado por la poderosa familia Colonna hasta el siglo XIII. El fundador del hospital de San Giacomo in Augusta fue el cardenal Pietro Colonna, en cuya decisión sin duda pesó la voluntad de su tío, el también cardenal Giacomo Colonna (PAschinI, P., I Colonna [Le grandi famiglie romane, XI], Istituto di Studi Romani Editore, Roma, 1955, p. 13).

49 Pitture che stanno fuori dell'hospedale di San Giovanni in Laterano, pitture in San Giacomo al Colosseo..., Biblioteca Apostólica Vaticana, Barb. Lat. 4408, foll. XXII-XLV.

50 Biblioteca Apostólica Vaticana, Vat. Lat. 9848, foll. 12v-20r.

51 Biblioteca Apostólica Vaticana, Vat. Lat. 15308.
} 


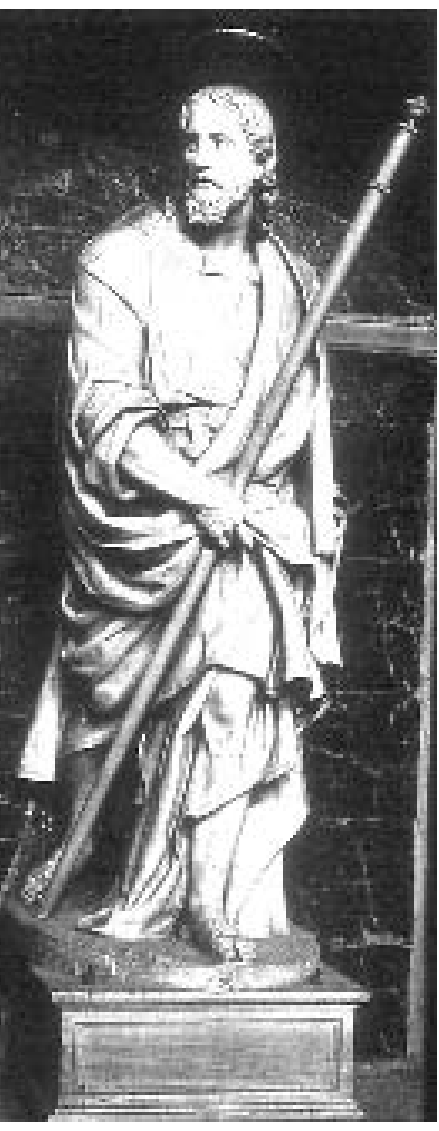

Fig. 13. Ippolito Buzio. Santiago el Mayor. Segundo tercio del siglo XVII. Roma. San Giacomo degli Incurabili.

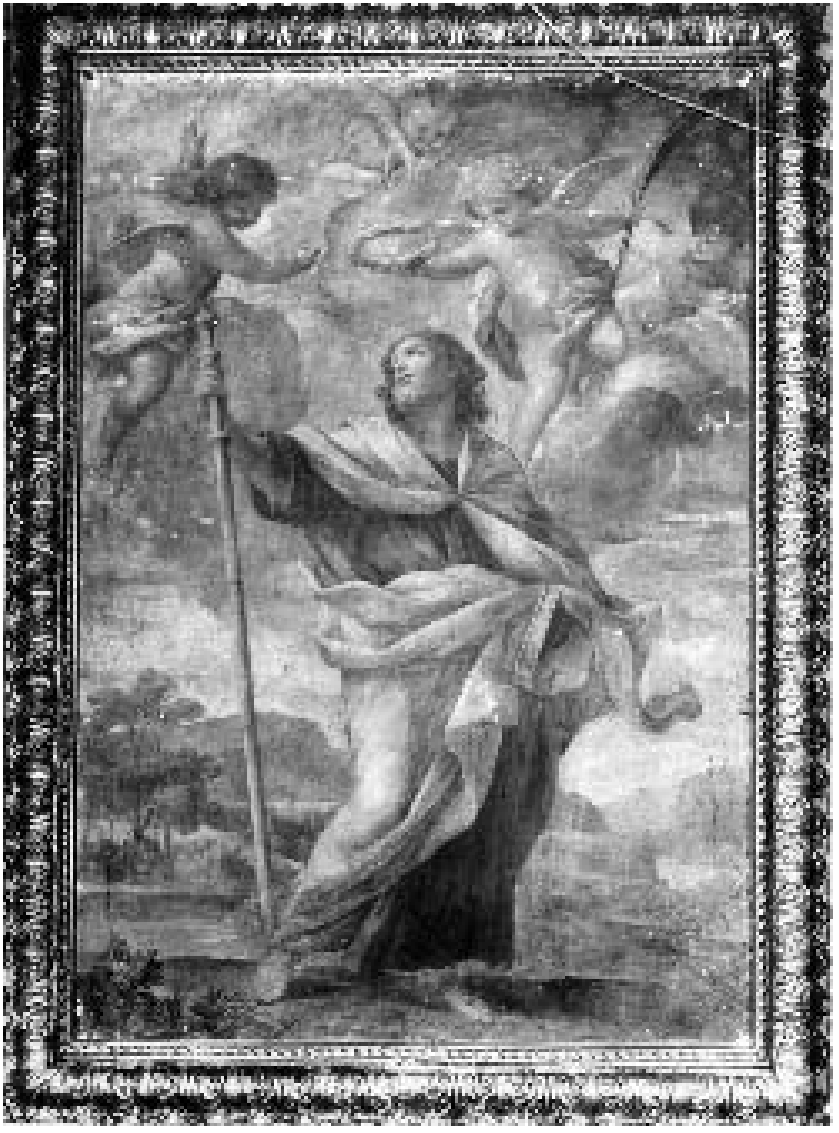

Fig. 14. Giovanni Francesco Romanelli. Santiago el Mayor. Segundo tercio del siglo XVII. Roma. San Giacomo alla Lungara.

escenas representadas destacaba un San Giacomo in Maestà y varios episodios de la leyenda del Apóstol, cuya iconografía ha sido parcialmente estudiada por Marcellii ${ }^{52}$, Waetzoldt ${ }^{53}$, Capitelli ${ }^{54}$ $\mathrm{y}$, de forma más completa, por Pasquale Iacobone ${ }^{55}$.

El estudio de este ciclo nos permite ahondar en dos temas. Por un lado, confirma el culto a Santiago ligado a la peregrinación y los peregrinos, pues tres de las cinco escenas de la leyenda del Santo muestran por primera vez en Roma sus milagros: el peregrino ahorcado, los treinta

52 Marcelli, F., "Un ciclo jacopeo 'inedito' e l'icona del Santo Salvatore, nella chiesa hospitaliera di San Giacomo al Colosseo in Roma", en Compostella, n. ${ }^{\circ} 22,1997$, pp. 18-22.

53 Waetzoldt, S., "Die Kopien des 17. Jahrhunderts nach Mosaiken und Wandmalereien in Rom", en Römische forschungen der Bibliotheca Hertziana, XVIII, Wien-München, 1964, pp. 34-35.

${ }^{54}$ CAPItelli, G., "L' 'ignobil masso': la perduta chiesa di San Giacomo al Colosseo...", en Roma moderna e con-

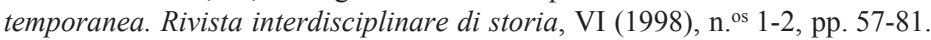

${ }^{55}$ Iacobone, P., "Gli affreschi iacopei della distrutta chiesa di San Giacomo al Colosseo di Roma", en Compostellanum, IL (2004), n. ${ }^{\text {os } 3-4, ~ p p . ~ 421-453 . ~}$ 


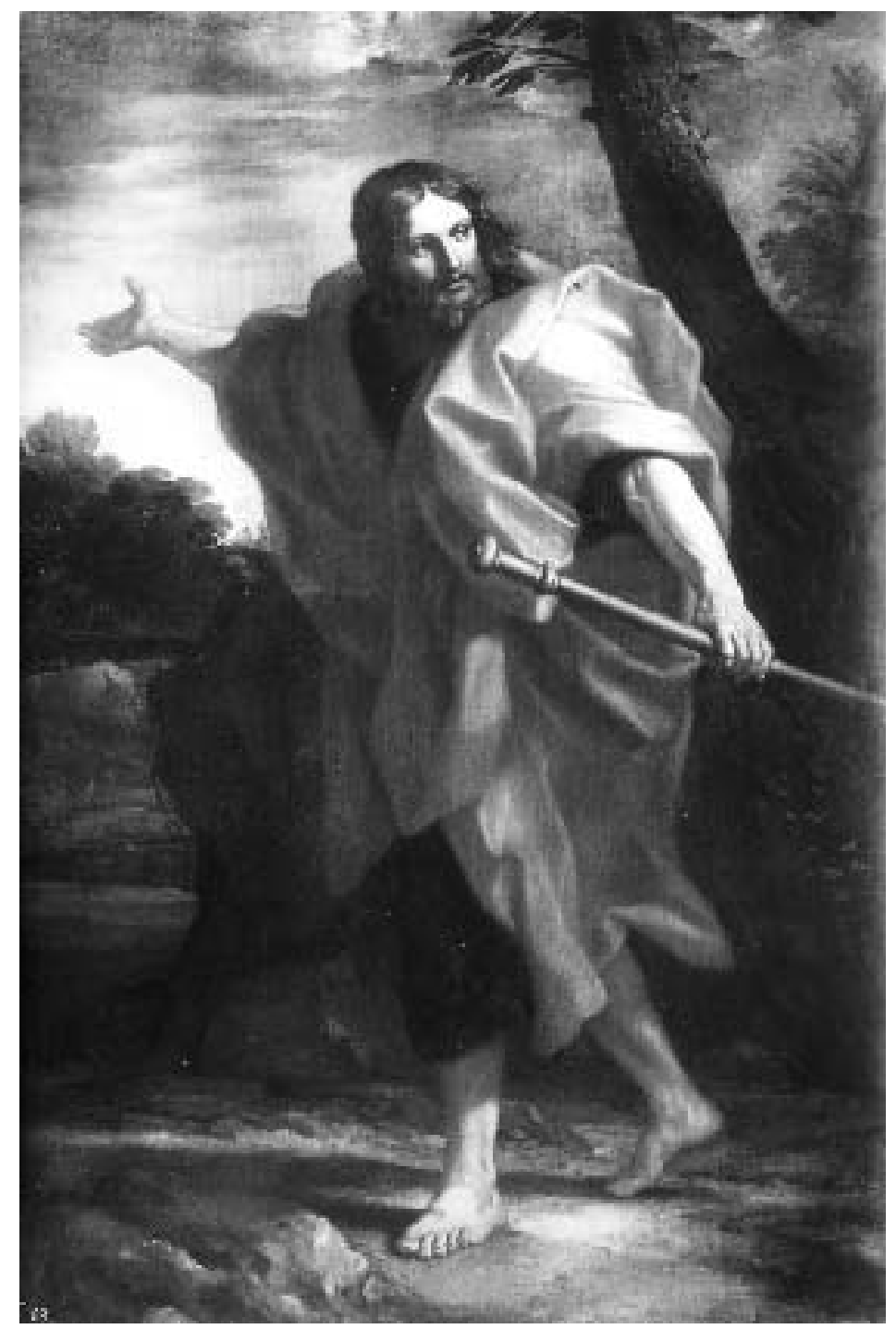

Fig. 15. Carlo Maratti. Santiago el Mayor. Último tercio del siglo XVII. Roma. Galleria Nazionale d'Arte Antica, Palezzo Barberini.

peregrinos loreneses y el mercader encerrado y liberado de una torre. Milagros obrados a los peregrinos que invocaban su protección y que eran vistos como "prueba del poder taumatúrgico del santo" "56. En segundo lugar, el ciclo evidencia el papel de las vías de peregrinación como difusoras de tipos iconográficos, pues las pinturas adoptan modelos utilizados en Parma, Padova o Pistoia unas décadas antes ${ }^{57}$, e incluso adoptan tipos compostelanos como la Maestà a los que

56 DíAZ y DíAZ, M. C., op. cit., p. 27.

57 Sobre la cristalización y difusión la iconografía jacobea en la Italia del siglo XIV véase: VÁzQuEZ SANTOS, R., Vida de Santiago el Mayor en el Legendario Húngaro de los Anjou, Xunta de Galicia [Colección Científica], Santiago de Compostela, 2005, pp. 49-61. 
incorporan soluciones de sus derivaciones en la via Francigena, como la escultura de plata del altar de Pistoia ${ }^{58}$, y en las vías francesas, cuyas esculturas y relieves recogían las influencias del relieve del tímpano del hospital de París ${ }^{59}$.

Lo más significativo del ciclo apenas descrito es el lugar en el que se encontraba. San Giacomo al Colosseo dependía de San Juan de Letrán y estaba dentro del circuito de la procesión que el clero lateranense realizaba con la célebre imagen "achereopita" del Salvador, la más importante de Roma durante todo el siglo XIV ${ }^{60}$, constituyendo un perfecto ejemplo de iglesia romana de peregrinación que, en consecuencia, debía reflejar una imagen de Santiago el Mayor aceptada y venerada por el clero y los peregrinos de la ciudad ${ }^{61}$.

El vínculo entre el culto a Santiago y la peregrinación se mantuvo en la Roma del siglo XV, reflejándose en la iconografía de las iglesias de titularidad jacobea, sobre todo en la nueva iglesia y hospital de San Giacomo degli Spagnoli, en la que Andrea Bregno (1418-1506) y su escuela cubrieron de conchas y bordones el sepulcro de su fundador, el obispo de Ciudad Rodrigo Alfonso de Paradinas (obispo, 1469-1485) ${ }^{62}$, y cincelaron esculturas del Apóstol sepulcros como el de Juan de Mella (cardenal, 1465-1467) ${ }^{63}$. La prolífica escuela formada en torno al célebre escultor fue también responsable de algunas de las esculturas del Santo peregrino que, gracias a la devoción privada, ornaron los sepulcros de altos dignatarios del clero romano: Jacopo Tebaldo da Collesciopoli (cardenal, 1436-1446), en Santa María sopra Minerva ${ }^{64}$, y Giacomo Ammanati Piccolomini (1422-79) y Giovanni Giacomo Schiaffinati (cardenal, 1451-1497) en Sant'Agostino ${ }^{65}$.

El principal ciclo jacobeo de la Roma del siglo XV se debe, precisamente, a un mecenas privado: "Manzino de Lutÿs" de la familia Mancini o Massimi. Se trata de un altar pintado en 1441 por Giovenale di Orvieto para la capilla de San Giacomo, hoy de San Michele Arcangelo, que la familia poseía desde el siglo XIV en la iglesia franciscana de Santa María Araceli ${ }^{66}$. Una minuciosa descripción del siglo XVII nos ha permitido reconstruir su programa iconográfico e, incluso, identificar las tres tablas que conformaban el banco ${ }^{67}$.

58 Véase: GaI, L., L'altare argenteo di san Jacopo nel duomo di Pistoia, Allemandi, Torino, 1984.

59 Véase: JACOMET, H., "Saint-Jacques: Une image à la Française? L'iconographie suscitée par la création de l'hôpital Saint-Jacques-aux-Pèlerins et ses prolongements", en RucQuor, A. (coord.): Saint Jacques et la France, Actes du Colloques des 18 et 19 janvier 2001, París, 2003, pp. 85-262.

${ }^{60}$ Sobre la importancia de la procesión y su recorrido véase Kessler, H. L., ZACHARIAS, J., op. cit., pp. 65-69.

${ }^{61}$ Una descripción de la iglesia de 1635 corrobora su carácter de "iglesia de peregrinación" al describir otros ciclos relativos a santos hospitalarios y ligados a la peregrinación (ToRRIGIO, F. M., op. cit., p. 151).

${ }_{62}$ Andrea Bregno habría inaugurado en la iglesia una tipología en los monumentos funerarios del obispo Paradinas y Rodrigo Zánchez de Arévalo (CAgLioti, F., "Sui primi tempi romani d’Andrea Bregno", Miterlungen des Kunsthistorischen Institutes in Florenz, XLI, 1997, pp. 213-253; KüHLENTHAL, M., “Andrea Bregno in Rom”, Römisches Jahrbuch der Bibliotheca Hertziana, Band. 32, 1997/98, pp. 234-235); VÁzquEZ SANTos, R., op. cit., 2001, pp. 714-715.

${ }^{63}$ Atribuido a Andrea Bregno o a su discípulo Luigi Capponi da Milano (c. 1445-c. 1515) (VÁzQuEZ SANTos, R., op. cit., 2001, pp. 714-715).

${ }^{64}$ Sepulcro atribuido a Andrea Bregno y Giovanni Dalmata (c. 1440-c. 1514) (KÜHLENTHAL, M., “Andrea Bregno in Rom", Römisches Jahrbuch der Bibliotheca Hertziana, Band. 32, 1997/98, pp. 179-272).

${ }^{65}$ El convento de Sant'Agostino sufrió profundas reformas arquitectónicas que determinaron el traslado de algunos monumentos sepulcrales a un claustro, entre ellos los dos citados, atribuidos por la crítica al círculo de Andrea Bregno (Montevecchi, B., Sant'Agostino, en Le Chiese di Roma Illustrate 17, Istituto Nazionale di Studi Romani, Fratelli Palombi Editori, Roma, 1985, pp. 192-93).

${ }^{66} \mathrm{La}$ existencia del retablo, su mecenas y pintor eran conocidos gracias a una inscripción publicada por Casimiro (Casimiro Romano, F., Memorie istori\$che delle chiese e dei conventi dei Frati Minori della provincia Romana. Roma, 1845, m. 5671, p. 192) y Forcella (ForCELla, V., Iscrizioni delle chiese e d'altri edifici di Roma. Dal secolo XI fino ai giorni nostri, 14 vol., Roma, 1869-84, I, p. 136).

${ }^{67}$ VÁzQUEZ SANTOS, R., "Un nuevo catálogo pictórico del Quattrocento italiano: La tabla de Camerino y el desaparecido ciclo jacobeo de Giovenale de Orvieto en Araceli”, en Archivo Español de Arte, LXXXI (2008), pp. 105-114. 
En el cuerpo principal del retablo estaban representadas las imágenes de Santiago el Mayor, con libro y bordón, y, en menor tamaño, las de san Esteban y san Lorenzo, mientras que las tres tablas del banco reproducían los tres milagros del Santo y varias escenas de la traslación marítima y terrestre de sus reliquias desde tierras de Jafa a Galicia. Entre los tres milagros se encontraban los dos más celebrados en Italia: el del peregrino ahorcado y el de los treinta peregrinos de Lorena, ambos ya representados en el ciclo del Colosseo. El tercero y más moderno era el enigmático milagro del caballero que surgió del mar cubierto de conchas (fig. 7), prodigio más ligado a la heráldica que a la peregrinación. El programa iconográfico, por tanto, vuelve a darnos la clave de la situación del culto jacobeo en la ciudad, mostrando a Santiago como peregrino y patrón de peregrinos pero, también, haciendo un guiño a la importancia de su rol de protector de "casate" o estirpes, confirmando el protagonismo del Apóstol entre las devociones privadas de la ciudad.

\section{Cambios iconográficos en la Roma "española": Del Santiago peregrino al Santiago "mataturcos"}

Como ya hemos apuntado, el final del siglo XV señala un punto de inflexión en el culto jacobeo que tendrá como principal consecuencia la paulatina supresión de iglesias bajo su titularidad. En este cambio, creemos, influyeron dos procesos que se estaban desarrollando en paralelo: la siempre creciente importancia y fortaleza del jubileo romano, frente a una peregrinación compostelana que empieza a debilitarse, y los cambios del culto ocasionados por la situación en el Mediterráneo y precipitados con rapidez desde la caída de Constantinopla en 1453.

A comienzos del siglo XV la peregrinación a Santiago todavía no había entrado en crisis pero carecía de la fortaleza de las centurias anteriores y, ciertamente, ya no podía ser útil como aliada. La Roma destruida por el abandono de los papas había renacido y los jubileos de 1475 $\mathrm{y}$, sobre todo, 1500, demostraron que la ciudad superaba con creces a cualquier otra meta de peregrinación. Frente a los elogiosos comentarios de Dante, encontramos ahora ataques y críticas lanzadas desde las principales guías para romeros, textos que desaconsejan la peregrinación a la tumba del hijo del Zebedeo, cuya importancia como meta se cuestiona con desventajosas comparaciones entre las indulgencias ofrecidas por el viejo santuario y las concedidas por las basílicas romanas ${ }^{68}$.

Respecto a los cambios en el culto, la situación política y militar en el Mediterráneo llevó paulatinamente a abandonar la devoción al Santo peregrino en favor del caballero o matamoros.

Desde finales del siglo XV la expansión del Turco constituía una amenaza para las propiedades de la Corona de Aragón, lo que en 1481 llevó a los Reyes Católicos a apoyar al papado en la batalla de Otranto. Nació entonces el nuevo rol de España como defensora de la iglesia, concretado en 1511 a través de una alianza formal con Roma y Venecia que, con altos y bajos, se mantuvo hasta la célebre victoria de Lepanto $(1571)^{69}$. En Roma la situación histórica apenas

\footnotetext{
68 Poco después del nacimiento de la imprenta se editaron los textos que hasta entonces circulaban en forma de manuscritos. Las guías Indulgentie \& Reliquie de le chiese di Roma, impresa en 1522-1523, y Le cose maravigliose della città di Roma, 1540, incluían frases desaconsejando a los peregrinos la peregrinación a Compostela que consideraban innecesaria dadas las muchas indulgencias que el peregrino podía obtener en las basílicas de Roma. Las dos guías fueron traducidas a numerosas lenguas vernaculares y se reeditaron sin cesar a lo largo del siglo XVI. Su influencia pervivió en algunos textos del XVII, como la guía de Totti, en la que las frases copiadas aparecen como un anacronismo en un momento histórico en el que el declive de Compostela coincidía con el máximo esplendor del Giubileo romano (VÁzQuez SANTOS, R., op. cit., 2001, pp. 828-830).

69 Dandelet, T. J., La Roma española. 1500-1700, Cátedra, Barcelona, 2002, pp. 33, 50.
} 


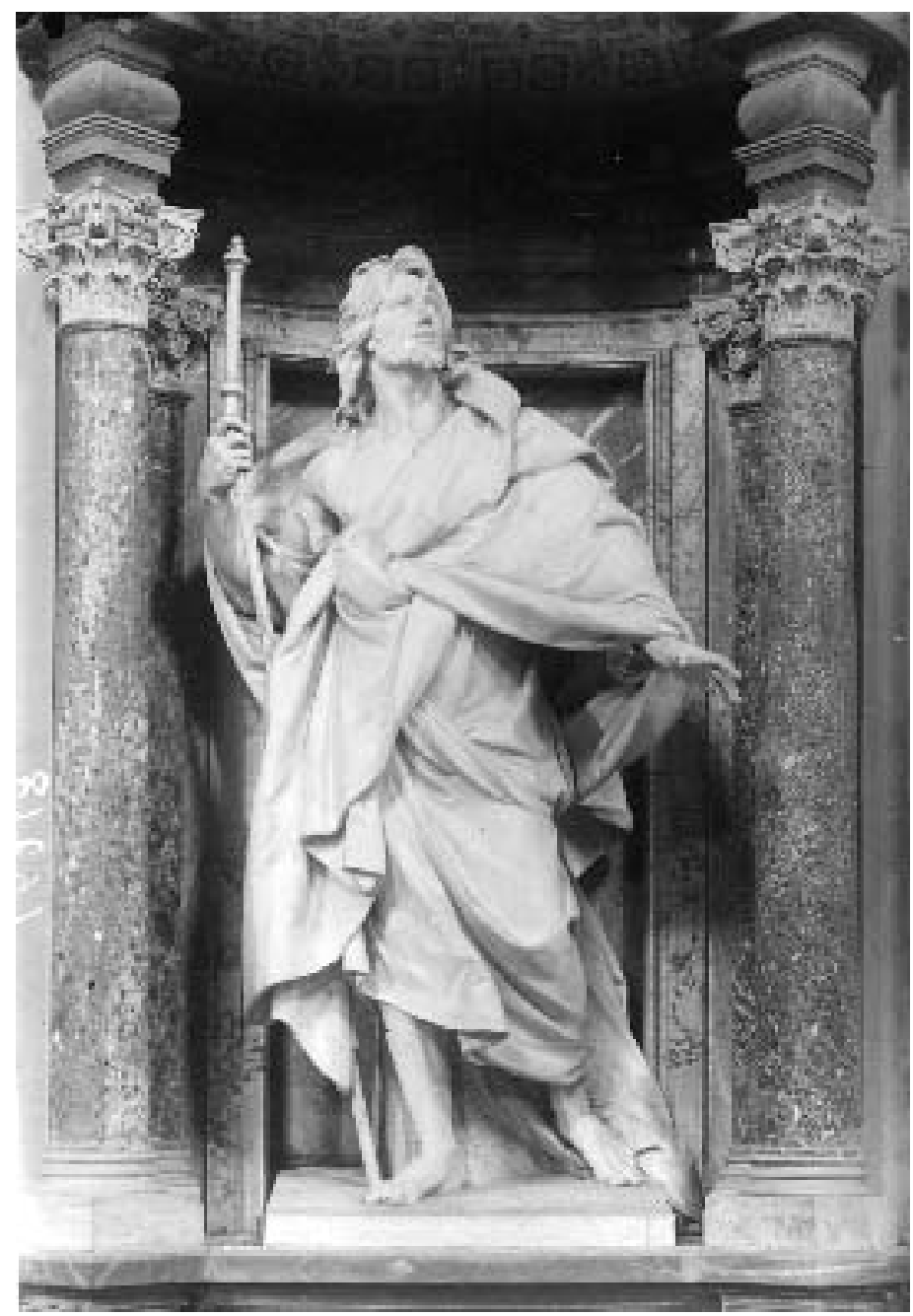

Fig. 16. Camillo Rusconi. Santiago el Mayor. 1715-18. Roma. San Giovanni in Laterano.

descrita empezó a repercutir en el culto a Santiago a partir de un suceso muy concreto: la capitulación de Granada en enero de 1492. La victoria de los Reyes Católicos fue aclamada en la ciudad papal, que veía ante ella tiempos de Cruzada, propiciando el uso de la imagen de Santiago como matamoros, defensor de la cristiandad y patrono de la Monarquía Hispánica. La nueva devoción estuvo ligada desde el comienzo a la obra pía española, la iglesia y hospitales de San Giacomo degli Spagnoli (fig. 8), responsable de la organización de los festejos de la caída de Granada. Podemos incluso fijar una fecha inaugural: el 19 de febrero de 1492, cuando Innocenzo VIII (papa, 1484 y 1492) asistió con la mayor parte de los cardenales a honorar al Apóstol en la iglesia española a la que, poco después, concedería indulgencia plenaria para el primer domingo de febrero y la fiesta de Santiago ${ }^{70}$.

70 VÁzquez SAntos, R., op. cit., 2001, p. 832, n. 24. 
El reflejo de esta trasformación del culto en la iconografía debió ser inmediato, aunque no podemos documentarlo hasta algunos años después, cuando en 1502 el gran pintor Antoniazzo Romano (c. 1430-c. 1510) ejecutó dos pinturas de Santiago "ad modum Yspanie" para la fiesta de la iglesia ${ }^{71}$.

Años después, en torno a 1517, Pellegrino da Modena (c. 1460-1523), uno de los alumnos de Rafael (1483-1520) que habían trabajado en las logias vaticanas, decoró en la misma iglesia la capilla de Jaime Serra (cardenal, ?-1517) con un ciclo de frescos dedicado a la leyenda del Apóstol (fig. 9). Algunas de las pinturas fueron destruidas en una restauración caso inmediata, pero el ciclo pictórico puede ser reconstruido a partir de fragmentos de frescos conservados en la iglesia de Santa María di Monserrato que, claramente, representaban la translación terrestre del cuerpo de Santiago $^{72}$. El resto de las escenas reproducen los episodios relativos a la conversión de los magos Hermógenes y Fileto, la curación y conversión del escriba Josías y, por primera vez en Roma, la batalla de Clavijo (fig. 10). No obstante, el ciclo se complementaba con la presencia majestuosa de una escultura de Jacopo Sansovino (1486-1570) (fig. 11) en la que Santiago sigue representándose como peregrino, adoptando una iconografía francesa claramente ligada a la peregrinación ${ }^{73}$.

El Santiago político y militar había tomado la ciudad y el clero romano le rendiría culto hasta los tiempos de Lepanto ${ }^{74}$.

\section{El Santiago apóstol y el Santiago peregrino en el siglo XVI: Devoción privada, cofradias y labor asistencial}

La devoción al Apóstol protector de peregrinos se mantuvo en el ámbito privado y en algunas de las iglesias bajo su titularidad, sobre todo en la iglesia y hospital de San Giacomo in Augusta, conocido en esa centuria como "degli Incurabili", que por su carácter asistencial vinculado a la peregrinación continuó sosteniendo una devoción que cada vez reflejaba menos la realidad de la época.

A lo largo del siglo XVI el hospital de Augusta sufrió una profunda transformación. El genovés Ettore Vernazza, fundador del Oratorio del Divino Amor, lo convirtió en una institución especializada en enfermedades contagiosas ${ }^{75}$ y en 1515 obtuvo de León X (papa, 1513-21) una bula que lo elevaba a Arcispedale degl'Incurabili ${ }^{76}$. Durante todo este proceso la administración del hospital estuvo en manos de una cofradía dedicada a Santiago, la única de la ciudad dedicada al Apóstol, que gracias a su titularidad jugó un importante papel en la poderosa comunidad española de Roma que, hasta la fundación de la cofradía de la Resurretione en San Giacomo degli Spagnoli en $1597^{77}$, la adoptó como una especie de cofradía nacional ${ }^{78}$. Esta cofradía se encargó

71 Antoniazzo Romano, Studien zur Quattrocentomalerei in Rom. Inaugural-Dissertation zur Erlangung des Doktorgrades der Philosophistchen Fakultät der Westfälischen Wilhelms-Universität zu Münster (Westf.). Vorgelest von Gisela Noehles geb. Doerk aus Königsberg. 1973, p. 284.

${ }^{72}$ Tal y como señalé en su día en Santiago e l'Italia, probablemente se trataba de las escenas de la milagrosa doma de los toros y llegada al palacio de la reina Lupa, aunque es posible que los fragmentos estudiados se refiriesen sólo a una de las dos escenas, dedicándose la otra a la traslación marítima (VÁZqUEZ SANTOS, R., op. cit., 2005, p. 855).

73 VÁzQuez SANTOS, R., op. cit., 2005, pp. 628-31; Ibidem, op. cit., 2005, pp. 851-859, figs. 6-15.

${ }^{74}$ Cuando en 1586 el ejército imperial reconquistó la ciudad de Colonia, el papa Sixto V “andó processionalmente da Monte Cavallo con 20 Cardinali alla Chiesa di San Jacomo de spagnoli...” (DANDELET, T. J., op. cit., p. 113).

75 Pecchiai, P., Montini, R. U., San Giacomo in Augusta, Le chiese di Roma Illustrate n. o 46, Edizioni "Roma", 1958, p. 15.

${ }^{76}$ La bula "Salvatoris Nostri", fechada el 19 de julio de 1515 (Pecchiai, P., Montini, R. U., op. cit., pp. 15-16).

77 Fernández Alonso, J., Santiago de los Españoles y la archicofradía de la Santísima Resurrección en Roma hasta 1754, “Anthologica Annua”, VIII (1960), pp. 279-329.

${ }^{78}$ Esta situación se hizo evidente tras el detenido estudio de los registros de la cofradía entre los años 1571 y 1618 (Archivio di Stato di Roma, Ospedale di San Giacomo, busta 359, documento 21). 
de organizar la fiesta del Apóstol durante todo el siglo XVI y parte del XVII, fiesta para la que la iglesia había obtenido indulgencia plenaria ${ }^{79}$. Durante todo este proceso el emblema del hospital fue una imagen de la Virgen y el apóstol Santiago junto a un enfermo ${ }^{80}$ y en las procesiones los cofrades llevaban como insignia un Santiago peregrino ${ }^{81}$.

El otro bastión del culto jacobeo en la ciudad fue la iglesia de San Giacomo Scossacavalli que, gracias a su pertenencia a la basílica de San Pedro, obtuvo numerosas gracias y concesiones. En 1520 se convirtió en sede de la Confratèrnita del SS. Sacramento, una de las más importantes de la ciudad, aprobada por León X (papa, 1513-21) en 1513 y elevada a Arciconfratèrnita por Gregorio XIII (papa, 1572-85) en $1578^{82}$. A lo largo de la centuria los cofrades consiguieron construir una nueva iglesia y obtuvieron indulgencia plenaria para el día 25 de julio ${ }^{83}$.

Respecto a la devoción privada, los ejemplos artísticos más sobresalientes están ligados a capillas de fundación anterior, con la excepción de la capilla de Santiago de Santa María sopra Minerva, de la que apenas existen noticias pero que, probablemente, fue fundada en el siglo XVI por un miembro de la familia Salviati. En los años centrales de esta centuria dicha capilla fue decorada con un cuadro de Marcello Venusti (1512/5-1579) (fig. 12), obra que alcanzó una enorme fama en la ciudad y llevó de nuevo la imagen del Santo peregrino a la poderosa iglesia dominica ${ }^{84}$.

\section{El siglo XVII: La herencia de Trento}

El siglo XVII podría verse como el verdadero punto de inflexión en la decadencia del culto a Santiago.

Las viejas cofradías de Augusta y Scossacavalli mantuvieron la gloria de Santiago cada 25 de julio pero, poco a poco, vieron mermado su papel, por el crecimiento y popularidad alcanzado por nuevas cofradías, más cercanas a la "pietas" y devoción post-tridentina. Paradójicamente entre estas últimas estuvo la cofradía de la Resurretione de San Giacomo degli Spagnoli, que desde su fundación en 1597 supuso un golpe indirecto al culto al Apóstol al concentrar todos sus esfuerzos en la organización de las procesiones y festejos del domingo de Pascua ${ }^{85}$.

A esta ausencia de un verdadero "motor" del culto jacobeo en la ciudad hay que sumar las consecuencias del concilio de Trento. Desde el inicio del siglo XVII Roma miraba a la tradición y una onda de reacción inundaba ciertos aspectos del arte: se reutiliza la Leyenda Dorada, vuelven a un primer plano los primeros mártires y protomártires. Los ejemplos son interminables: San Felipe y Santiago el Menor en la iglesia de los Santos Apóstoles, San Pedro y San Pablo aparecen en su suplicio en Santa María Traspontina, San Mateo en San Luis de los Franceses... Las representaciones de los apóstoles y sus martirios invadieron la ciudad más dogmática del orbe católico, difundiendo un culto oficial y una iconografía claramente ortodoxa ${ }^{86}$.

79 Guida Angelica. Per visitare le chiese, che sono dentro e fuori Roma tutto l'anno..., Roma, Pietro Leone, 1700, p. 35.

80 “... l'Imagine della Beata Vergine e di S. Giacomo apostolo, sotto le qualli aggionse una cariola con l'inferno sopra, che in atto di rendimento di grazie sta rivolto alla gloriosissima Vergine ed all'apostolo san Giacomo" (ALvERI, G., Della Roma in ogni stato, Roma, Celsi, 1964, II, p. 59).

81 "Non vesteno sacchi, ma per insegna usano un S. Iacomo in forma di pellegrino, con due carrete alli piedi, dentrovi uno stroppiato per ciascuna” (FAnUcCi Senese, C., Trattato di tutte l'opere pie..., p. 204).

82 C. Fanucci Senese, Trattato di tutte l'opere pie, pp. 243-244; F. Franzini, Roma antica e moderna, p. 67; C. B. Piazza, Opere pie di Roma descritte secondo lo stato presente, Roma, G. Battista Sussotti, 1679, p. 481.

${ }^{83}$ Guida Angelica, cit., p. 35.

${ }^{84}$ VÁzQuez SANTOS, R., op. cit., 2005, pp. 842-44.

85 Fernández Alonso, J., op. cit.; VÁzQuez Santos, R., op. cit., 2005, pp. 830-36.

${ }^{86}$ Emile Malê habla de un fenómeno nacido a partir de la revisión crítica del siglo XVII: "Ce travail critique du XVII siècle sur les Actes des martyrs et, en particulier, sur les Actes des martyrs romains, demeura enfermé dans un 
El efecto más inmediato sobre la iconografía de Santiago el Mayor fue la recuperación de su imagen apostólica y, consecuentemente, la paulatina desaparición de los hábitos y emblemas de peregrinación. Las esclavinas, sombreros y conchas de la escultura de Sansovino (1486-1570) y la pintura de Venusti (1512/5-1579) dieron ahora paso a las esculturas de Buzio (1578-1659) para San Giacomo in Augusta (fig. 13), la pintura de Romanelli (1610-1662) para San Giacomo alla Lungara (fig. 14) o los santiagos de los apostolados de Carlo Maratti (1625-1713) (fig. 15) y Camillo Rusconi (1658-1728) (fig. 16), imágenes míticas, clásicas y casi desnudas que en cierto sentido parecen sacadas del mundo medieval ${ }^{87}$.

Paralelamente las nuevas corrientes críticas que llegaron a Roma de la mano de García de Loaysa y fueron adoptadas por Baronio, el teólogo más influyente de la Roma de comienzos del siglo XVII, ofrecían una nueva lectura que, en su purismo "evangélico", negaba la predicación de Santiago en tierras de España ${ }^{88}$.

Por último tenemos que recordar el papel determinante de las nuevas devociones "nacionales" en la crisis del culto jacobeo. Particularmente importante fue la competencia de santa Teresa de Ávila, canonizada en los años posteriores a Trento, y la devoción de la Virgen del Pilar, muy reforzada por el impulso dado en el Concilio al culto mariano. A pesar del aparente triunfo del Apóstol en la lucha por el patronazgo de España ${ }^{89}$, ambos cultos continuaron amenazando el papel de Santiago a lo largo de los siglos XVII y XVIII, particularmente la Virgen del Pilar que relegaba a Santiago a un simple episodio de su propia leyenda. La situación tuvo su reflejo en la ciudad de Roma donde poco a poco se implantaron las nuevas iconografías, siendo la Virgen del Pilar la más ligada a las iglesias nacionales españolas ${ }^{90} \mathrm{y}$ otras de culto jacobeo ${ }^{91}$.

Fecha de recepción: 20-V-2009

Fecha de aceptación: 15-VII-2009

petit cercle d'érudits; il n'eut aucune influence sur l'art qui resta fidèle à touts les anciennes traditions. Le clergé a Rome se montra aussi respectueux du passé que Baronius, il continua à lire les Actes des martyrs romains et à en proposer les épisodes aux artistes" (MÂLE, E., L'Art Religieux après le Concile de Trente. Étude sur l'iconographie de la fin du XVI siècle, du XVII, du XVIII siècle. Italie-France-Espagne-Flandres, Paris, Librairie Armand Colin, 1932, p. 134).

${ }^{87}$ Las consecuencias del Concilio de Trento en la iconografía de Santiago el Mayor en la ciudad de Roma han sido ya estudiadas en VÁzquez Santos, R., "Santiago el Mayor en el Barroco Romano. Rusconi, Maratti, Romanelli", en Cuadernos de Arte e Iconografia, XV, 30 (2006), pp. 285-298.

88 Herbers, K., Politica y veneración de santos en la Península Ibérica. Desarrollo del "Santiago político", Fundación Rutas del Románico, 2006, pp. 15-17; Rey Castelao, O., La historiografía del Voto de Santiago. Recopilación crítica de una polémica histórica, Santiago de Compostela, 1985, pp. 58-146.

89 Aunque Felipe IV (1621-1665) reconoció el patronato apostólico, en 1700 el testamento de Carlos II volvió a mencionar el patronato de santa Teresa (Herbers, K., op. cit., 2006, pp. 16-17). Por su parte el culto a la Virgen del Pilar siguió desarrollándose a lo largo de los siglos XVII y XVIII, llevando al papa Clemente XII (1730-40) a aceptar el 12 de octubre como fecha para la celebración de la "festividad de la Virgen María Aparecida en Carne Mortal" [Lacarra, M. ${ }^{a}$ C., Ansón Navarro, A. y Boloqui Larraya, B., "Zaragoza Barroca”, en G. Fatás Cabeza (coord.): Guía histórico-artística de Zaragoza, Zaragoza, Ayuntamiento (Servicio de acción cultural), 1991].

${ }_{90}$ Numerosas fuentes reflejan la existencia de una pintura de la Virgen del Pilar en la iglesia de Monserrato que atribuyen a Carlo Saracino Veneziano (NibBy, A., Itinerario di Roma e delle sue vicinanze, Roma, 1870 (1. ${ }^{\mathrm{a}}$ ed., 1827), p. 426) o a Francisco Preciado (VASI, M., Itinerario istruttivo di Roma, Roma, 1794, vol. II, p. 637).

91 Tenemos noticia de la existencia de una representación de la aparición de la Virgen del Pilar a Santiago en San Giacomo in Augusta, obra fechada durante el papado de Paolo V (1605-1621) debida al pintor Francesco Zucchi (G. Baglione, Le vite de' pittori, scultori ed architetti..., 1642, ed. Fac-simile a cira di Valerio Mariani, Istituto d'Archeologia e Storia dell'Arte, Roma, 1942, pp. 102-103. 